\author{
دراسة تأثير التسربات النفطية على نوعية المياه السطحية

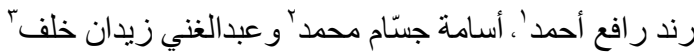

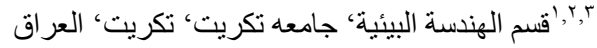

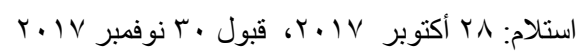

\begin{abstract}
الخلاصة

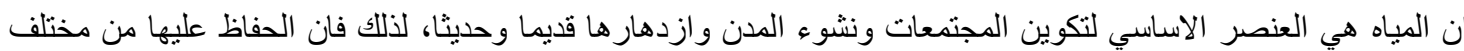

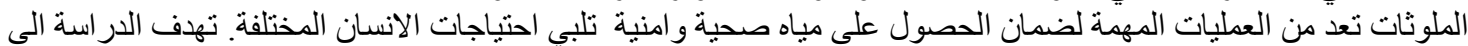

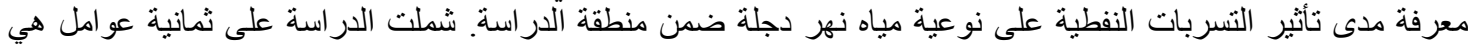

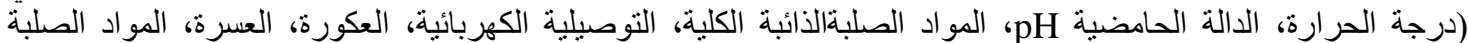

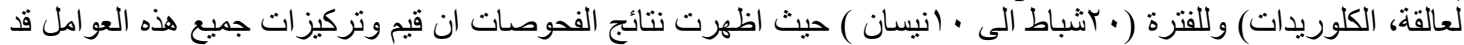

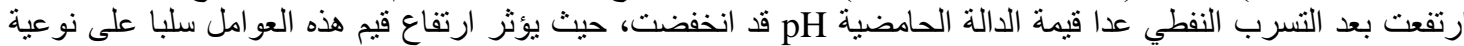

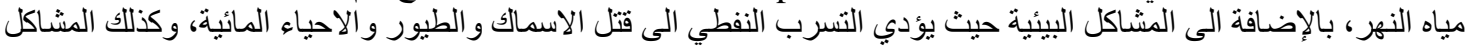

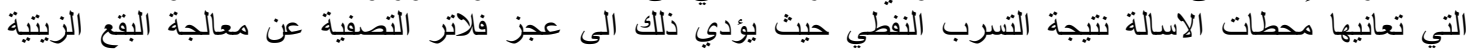

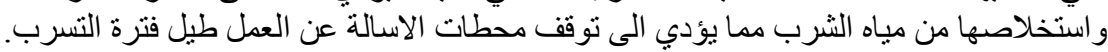

الكلمات المفتاحية:التسربات النفطية، التلوث البيئي، التلوث النفطي، مياه النهر
\end{abstract}

بالتو ازن البيئي في الارض ، او تقلل من جودة او قيمة الحياة

يمكن تقسيم التلوث البيئي الى ما يلى (الاحيدب

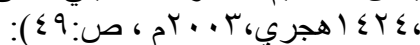

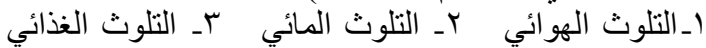

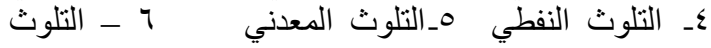

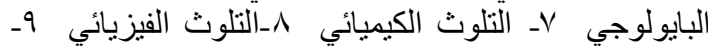

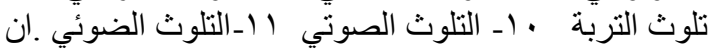

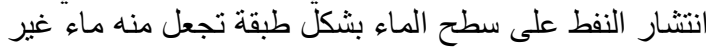

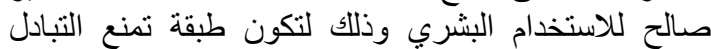

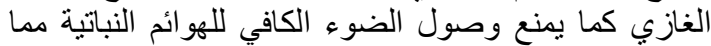

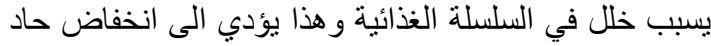

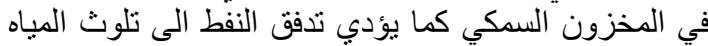

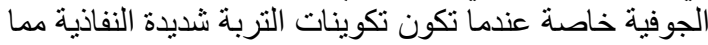

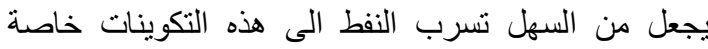
بمصاحبة مياه الامطار. ومن اهم الطرق للتخلص من التسربات النفطية في المياه هي:

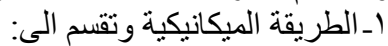
اـ إستخدام الحواجز الطافية. بـ استعمال المو اد الماصة التي تعرقل حركة البقعة.

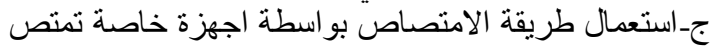
البقع النفطية. دــاستعمال اجهزة تقوم بقتط طبقة النفط السميكة الطافية على

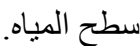

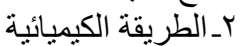

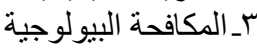

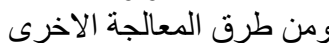

عـ الحرق: بإمكانه ان بقلل النفط في اليباه اذا استخدم بشكل

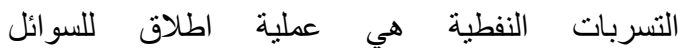
الهيدروكربونية البترولية في البيئة وتمثل شكلا من اشكال التلوث و هذا المصطلح يشير الى النسكاب النفط في اي بيئة مائية ويستغرق تنظيف النفايات النفطية شهورأ او حتى النى

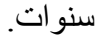
التلوث هو كل ما يؤثر في جميع عناصر البيئة بما فيها

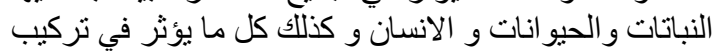

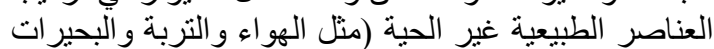

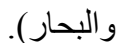

والتلوث النهري هو ادخال المادة او الطاقة الى البيئة

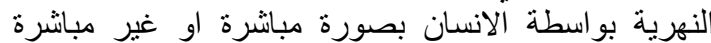

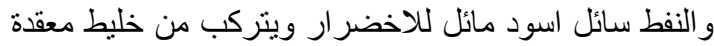
من المواد الهيدروكربونية والتي تنتركب اساساً من الكربون

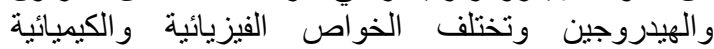

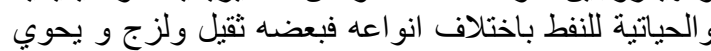

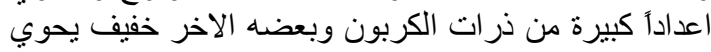
اعدادأ اقل نسبياً من ذرات الكربن الكربون كما ان نسبة الكبريت فية تختلف من نوع لأخر.

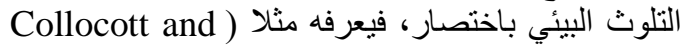

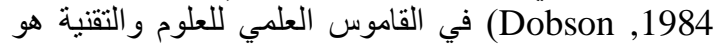

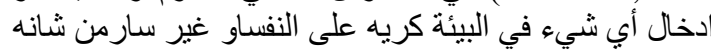

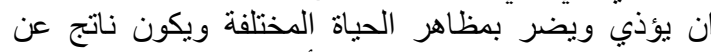

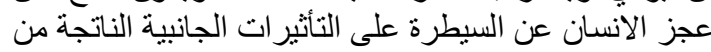

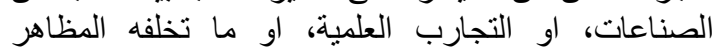

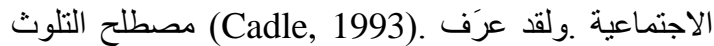
البيئي في موسوعة جرولير الدولية يثار اليه بما يلي :

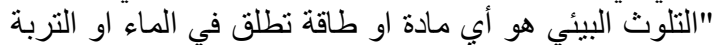
او الهواء لفترة او مدة طويلة من شانها ان تؤذي الئ او تضر التر

* Corresponding author:

Dr. Rand, R. Ahmed

$\bowtie$ randrafi3@tu.edu.iq 
النفطي الذي طر أ عليه من خلال اجر اء الفحوصات المختبرية

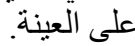
جمع العينات: بغية الحصول على افضل النتائج التحليلية

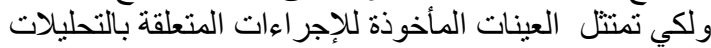

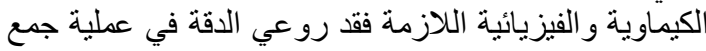

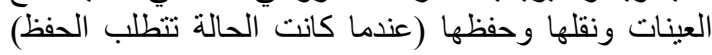

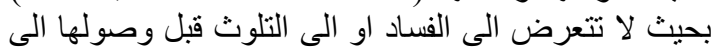
المختبر.

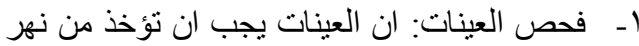
دجلة و تفحص في مختبر البيئة في هندسة البيئة

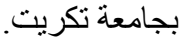
r-ـ مواقع اخذ العينات والفترة الزمنية لإخذها: ان العينات كانت تنوخذ من نهر دجلة عند مأخذ العند المياه

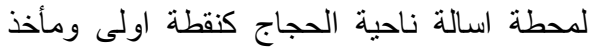

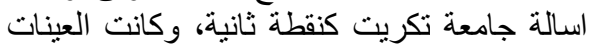

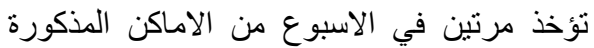

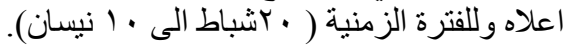

النتائج و المناقثة: من خلال النتائج التي ظهرت لنا، النا، يمكن مناقثة تأثير العو امل التي تمت در استها على نو عية المياه كما يلي:

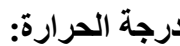

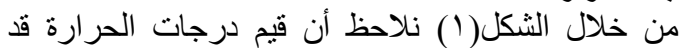

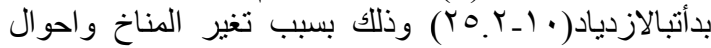

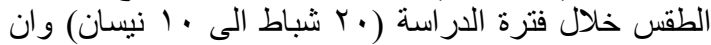

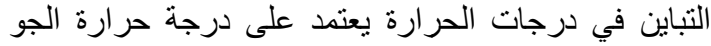

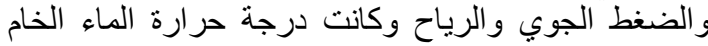

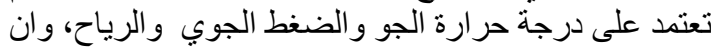

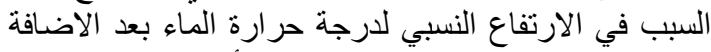

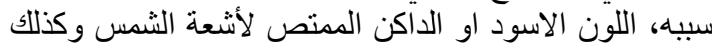
الطبقة التي يكونها النفط على سطح الماء التهن والني تؤدي الى لى

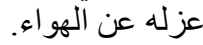

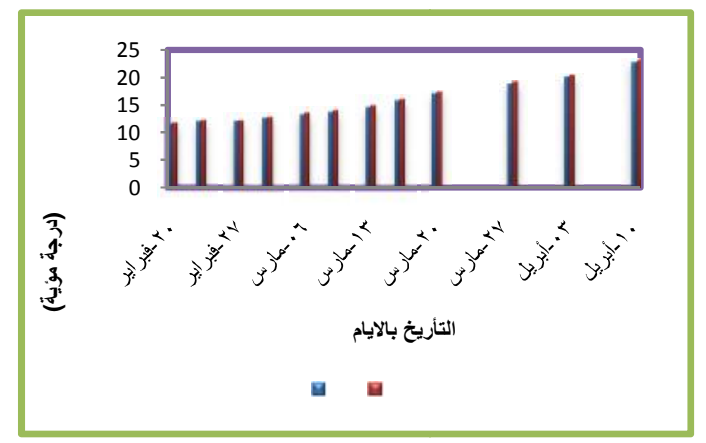

شكل( (1) يبين قيم درجات الحر ارة للماء قبل وبعد اضافة النفط. الالة الحامضية(1) من خلال الثُكل رقم (Y) نلاحظ بان هناك تباين في قيم

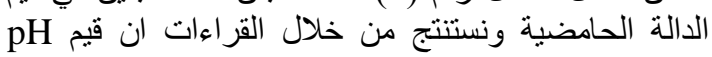

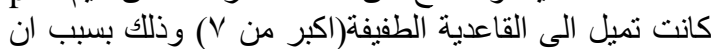

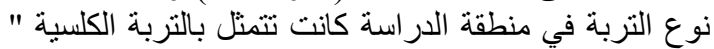
وجود كربونات الكالسيوم" التي تعد احد التئ الهم المسبيات

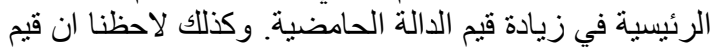

هـالانتظار و المشاهدة: في بعض الحالات التخفيف الطبيعي

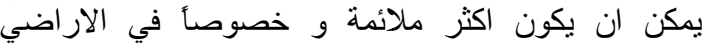

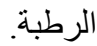

قام الباحثان (Pesce and Wunderlin, 2000) باستعمال مؤشر المياه لتقييم التأثيرات السلبية الناتجة عن

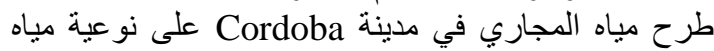
نهر suquia في الارجنتين. قام (Pratrick et al., 2005) باستخدام مؤشر نو عية المباه

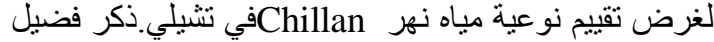
في مصدره (تسيير مخاطر الصحة العامة والسلامة البيئية 2008) ان التلوث النفطي يلحق اضرارَ النقاً بالنظام البيئي

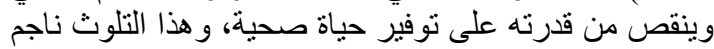

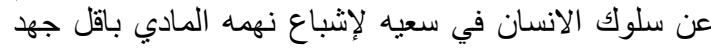

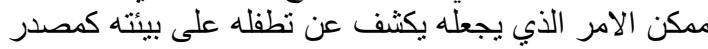

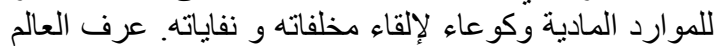

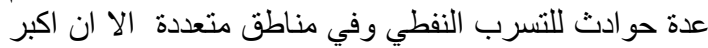

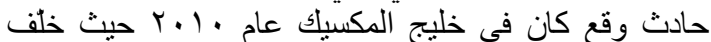

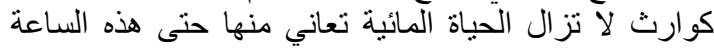

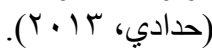

الهيف من الاراسة:

1- ـ دراسة نوعية مياه نهر دجلة ضمن منطقة الدار اسة.

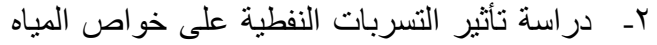

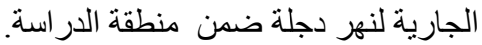

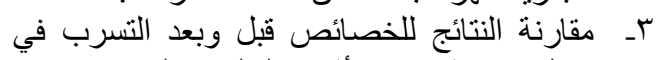

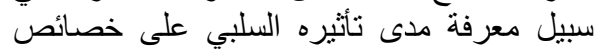
مياه النهر.

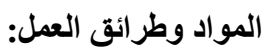
في الوقت الذي اجريت فيه الدراسة لم يكن هنالك أي وجود

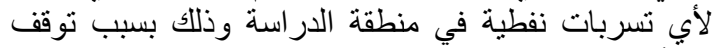

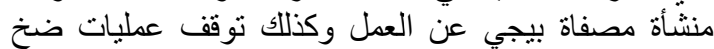

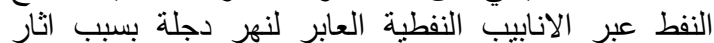

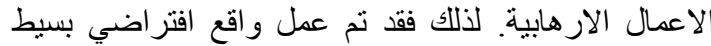

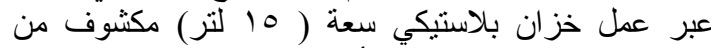

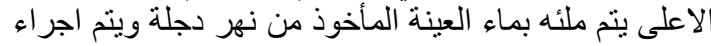
الفحوصات المختبرية بعد ذللك تضاف كمية من النفط الخام

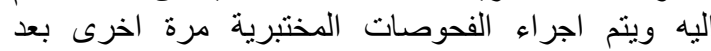

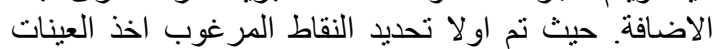

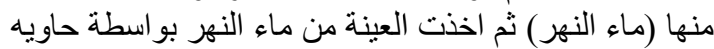

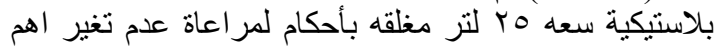

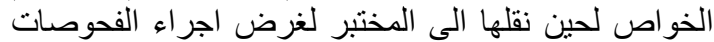

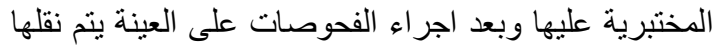

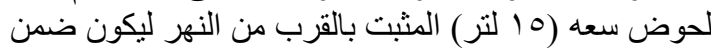

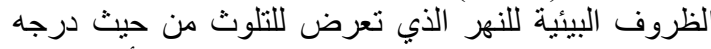

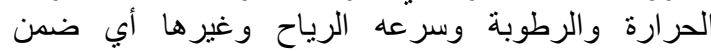
الظروف الطبيعية للنهر ثم تم اضافه نموذج الزئه الزيت و والذي تم

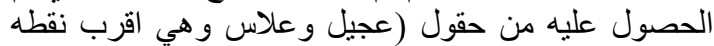

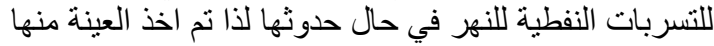

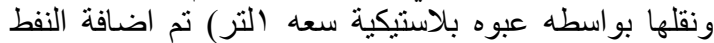

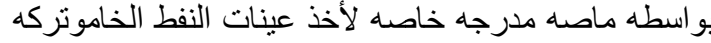
لمده اسبوع لمعرفه مدى تغير مواصفات المياه بعد التلوث 
قيم درجات الحرارة، وكذلك ارتفاع منسوب المياه لنهر دجلة النها

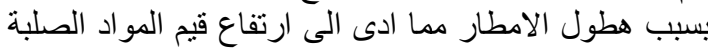

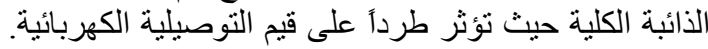

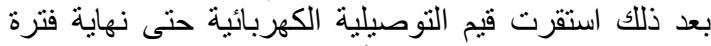

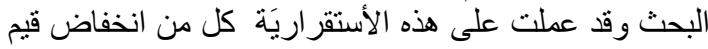

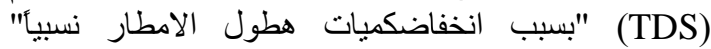

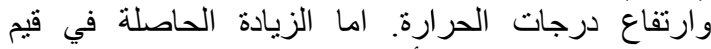

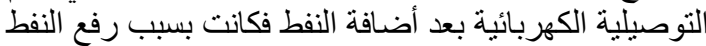
لدرجة حر ارة الماءو وقيم المو اد الصلبة الذائبة الكلية كذلك.

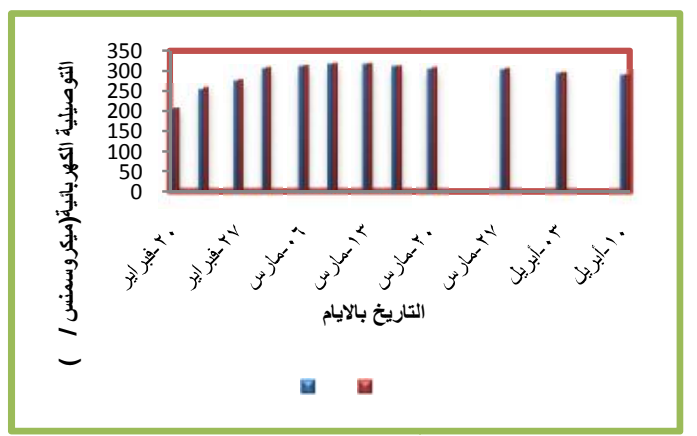

شكل(ع ) يبين قيم التوصيلية الكهربائية للمياه قبل وبعد اضافة النفط.

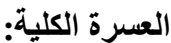

من خلال الشكل (0) الموضح النهاه الثناه نلاحظ ان قيم العسرة

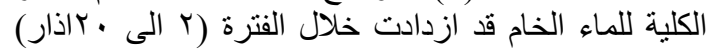

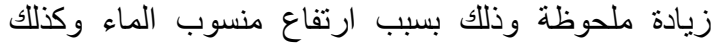

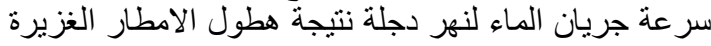

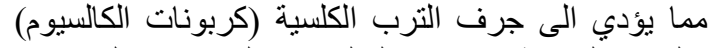

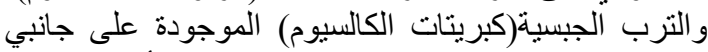

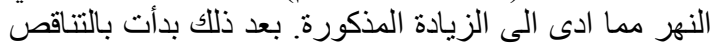

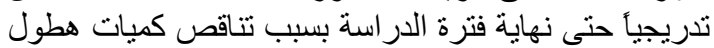

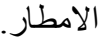

اما بالنسبة للزيادة النسبية الحاصلة في قيم العسرة على النى

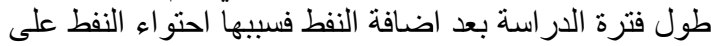

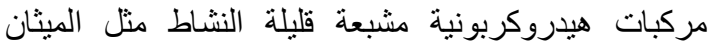

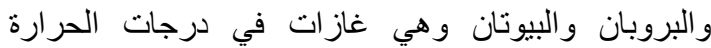

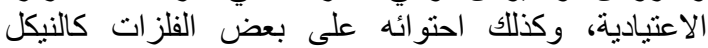

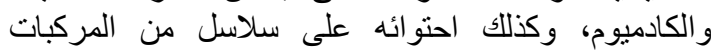
الكبريتية والنتروجينيةوالاروماتية التي تعمل على على زيادة

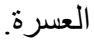

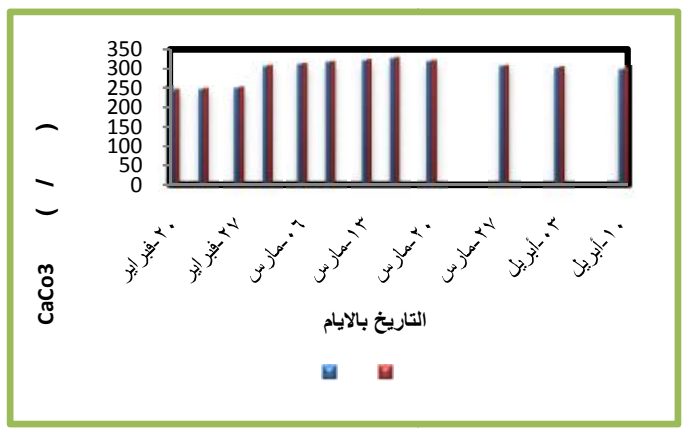

شكل (•) يبين تر اكيز العسرة الكلية للمباه قبل وبعد اضافة النفط.
pH

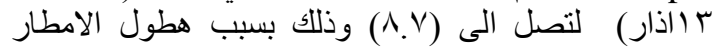

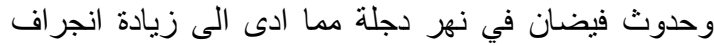

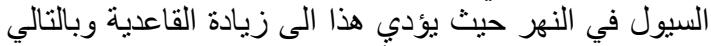

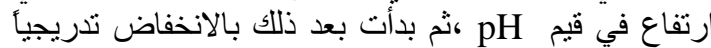

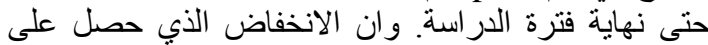
قيمه الرقم الهيدروجيني بعد اضافة النفط سبيه الخانيه الحامضية

النسبية التي يتصف بها النفط الخام،(Concawe,2004).

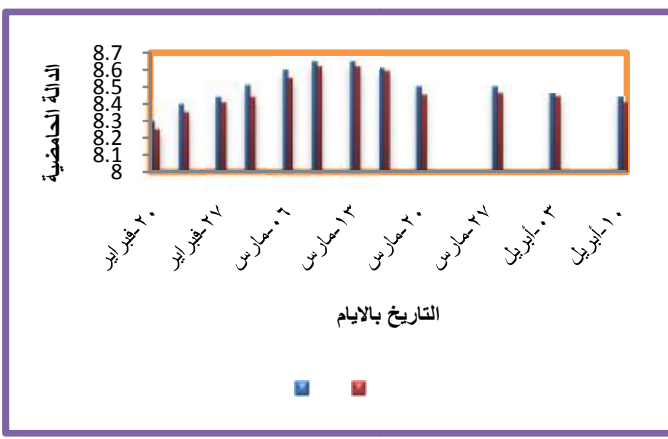

ثكل (r) يبين قيم الدالة الحامضية للمباه قبل وبعد اضافة النفط.

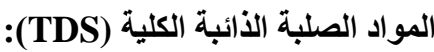

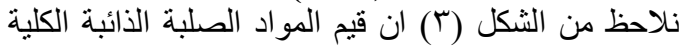

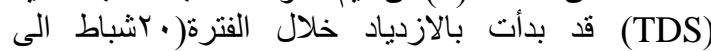

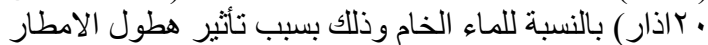

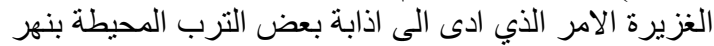

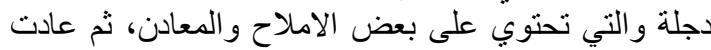

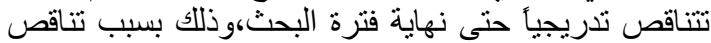
كميات هطول الامطاروان الارتفاع النسبي في قيم فيم (TDS)

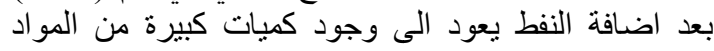

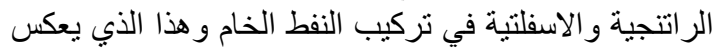

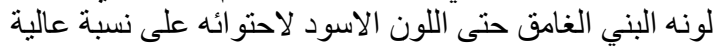

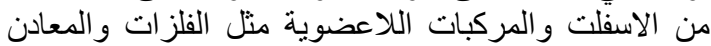
اضنافة الى كثافته العالية.

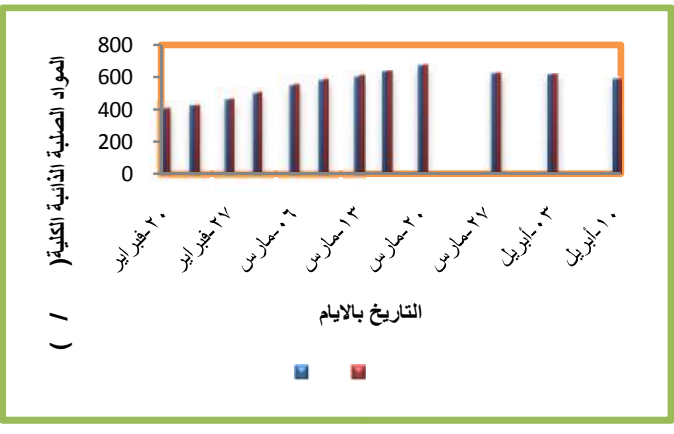

شكل(rّ) يبين نر اكيز (TDS) للمياه قبل وبعد اضافة النفط. التوصيلية الكهربائية:

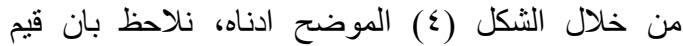
التوصيلية الكهربائية للماء الخام قد بدئت بالازدياد في بداية بادية

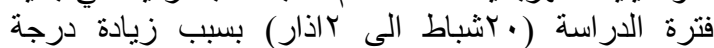

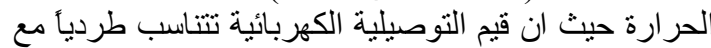


بالازدياد التدريجي، وذلك بسبب فيضان نهر دجلة لكثرة

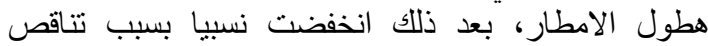
كميات هطول الامطار وبالتالي انخفاض مسنوى فئن فيضان

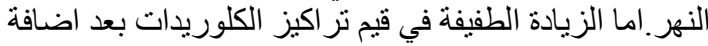

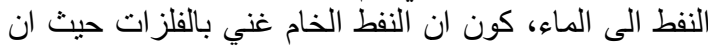

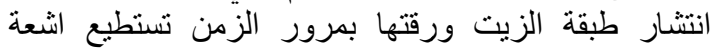

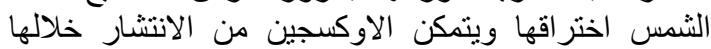

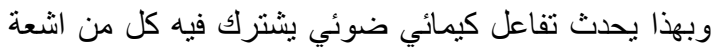

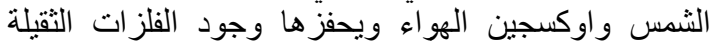

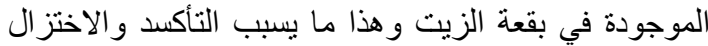
وزيادة اتحاد الفلزات والاتيونات ولات وتكون الاملاح المعدنية

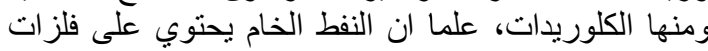

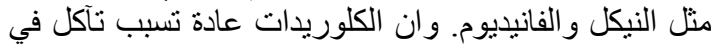

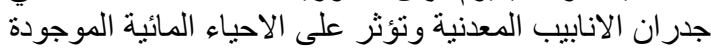

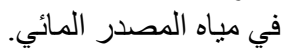

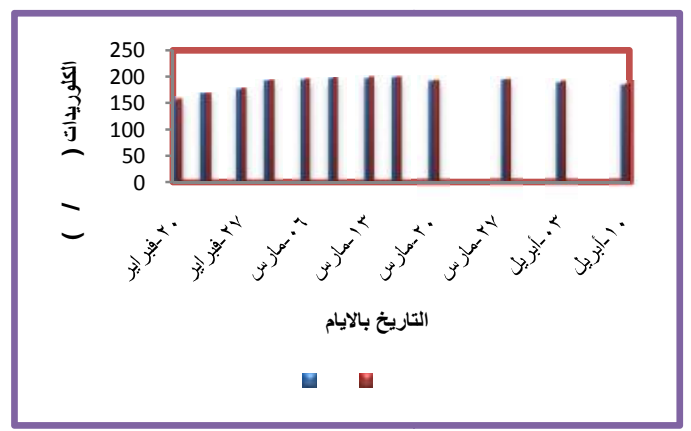

ثُكل(^) يبين تراكيز الكلوريدات للمياه قبل وبعد اضافة النفط

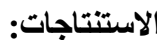

اعتماداً على النتائج المتحصلة من الدراسة الحالية يكمن

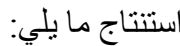

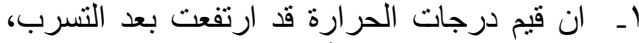
و هذا يسبب اضر ار لـار للأحياء المائية.

r- انخفاض تركيز الاوكسجين في الماء نتيجة الطبقة

الزيتية العليا الطافية في المين في الماء وقلة ذوبان الطبة الاوكسجين في الماء.

r- ـ تغيرات في اللبيئة المائية للنهر وكما بينت في تئي

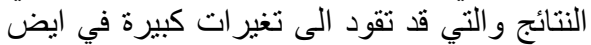

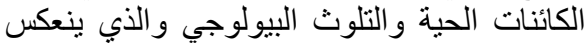

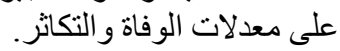

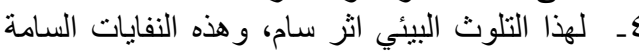

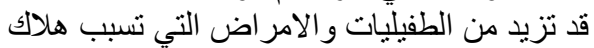
الطيور و الاسماك و الاحياء المائية.

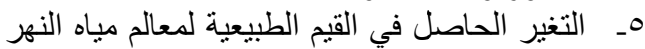

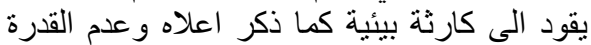

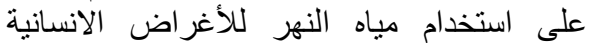
وتوقف محطات تصفية المياه. التوصيات: من خلال الدراسة والنتائج التي ظهرت لنايمكن لنا ان

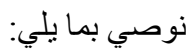

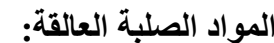

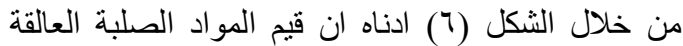

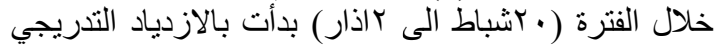

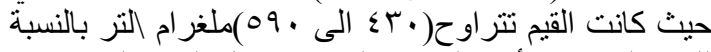

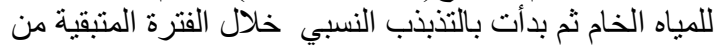

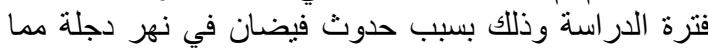

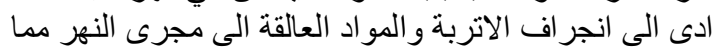

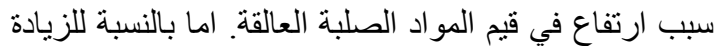

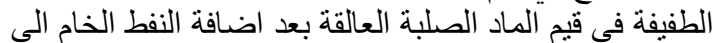

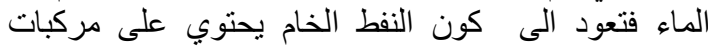

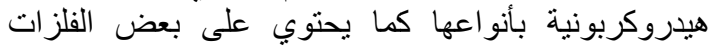

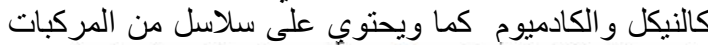
كبريتية والبار افينيبة مما ادى ألى زيادة قيم الموادئ من الصيلية

العالقة. - مبرة

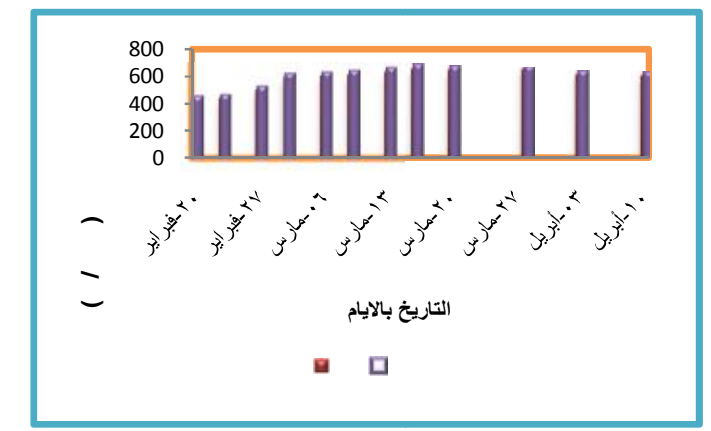

شكل (†) يبين تر اكيز المواد الصلبة العالقة للمياه قبل وبعد اضافة النفط.

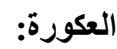

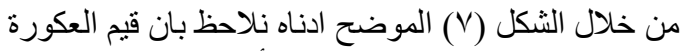

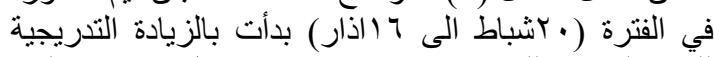

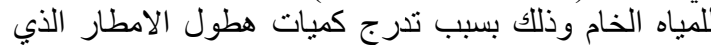

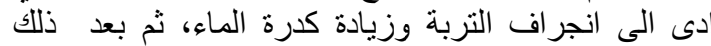

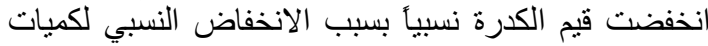

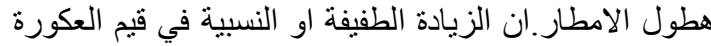

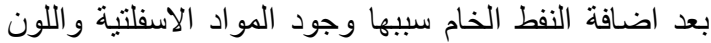
الاسود او البني الغامق للنفط الخام . لإمام

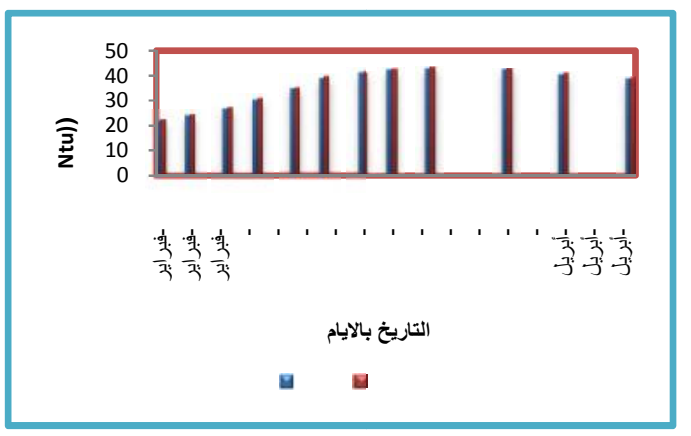

شكل(V) يبين قيم العكورة للماء قبل وبعد اضافة النفط الخام.

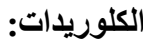
من خلال الثكل (^) الموضح ادناه نلاحظ بان قيم

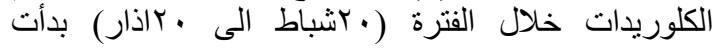


Al - Lami, A.A., Kassim, Th. and Al Dylymei, A.A. (1999). " Limnological Study on Tigris River, Iraq ", The Scientific Journal of Iraq Atomic Energy Commission, Vol.1p.p. $83-$ 98.

Clark, R.C. and Brown, D.W. (1977). Petroleum: properties and analysis in biotic and abiotic systems. In Malins (Ed) Effects of Petroleum on Arctic and Subartic Environments and Organisms, Nature and Fate of Petroleum. Academic Press, Inc., New York, :1-89.

Concawe (2004). Trends in Oil Discharged with Aqueous Effluent from Oil Refineries in Europe: 2000 Survey. Concawe (The Oil Companies European Association for Environment, Health \& Safety in Refinery\& Distribution, Beljum) Report, 4(4)9:4-9.

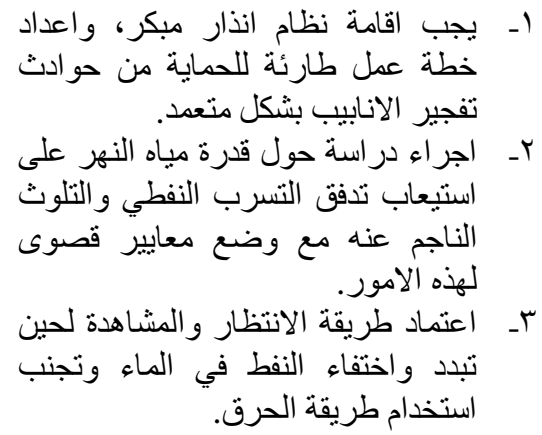




\title{
Study the effect of the petroleum leakage on the grade of the shallowness water
}

\author{
Rand R. Ahmed ${ }^{1}$, Asama J. Mohamed ${ }^{2}$ and Abd Al g. Zedan ${ }^{3}$ \\ Environmental Engineering Department, University of Tikrit, Tikrit, Iraq.
}

\begin{abstract}
Water is the origination of the life and It's essential ingredient to growth the society. Therefore we must preservation is from several contaminateit happened to guarantee obtainment a clean water that meeting with the several purpose and the human needing. This search aims to studies the effect of leakage petroleum on the grade of Djlla river by investigate the specifications (Temperature, $\mathrm{pH}$, TDS, conductivity, water hardness, TSS, Turbidity, Chlorides ) for period (20 February to 10 April).This study establish that all this factors aforesaid was increase after the leakage of petroleum beyond the $\mathrm{pH}$ value was decrease, increase of this factors can affecting on the specific water and aquatic life (fish, bird and others ). Leakage of petroleum can interfere with our wastewater treatment process because the oil can coalesce and solidify therefore water level sensor and pump switches can get fouled by oil causing pump fail to start over and above difficulty to separating the oil from water.
\end{abstract}

